\title{
Intraspecific variations in the venom peptidome of the ant Odontomachus haematodus (Formicidae: Ponerinae) from French Guiana
}

\author{
Axel Touchard', Alain Dejean ${ }^{1,2,3}$, Pierre Escoubas ${ }^{4}$, Jérôme Orivel' \\ I CNRS, UMR Ecologie de Forêts de Guyane (AgroParisTech, CIRAD, CNRS, INRA, Université de Guyane, \\ Université des Antilles), Campus agronomique, BP 316, 97379 Kourou cedex, France 2 Université de Toulou- \\ se; UPS, INP, Laboratoire Écologie Fonctionnelle et Environnement, 118 route de Narbonne, 31062 Toulouse, \\ France 3 CNRS; Ecolab (UMR-CNRS 5245), 118 route de Narbonne, 31062 Toulouse, France 4 Venome- \\ Tech, 473 Route des Dolines - Villa 3, Valbonne 06560, France \\ Corresponding author: Axel Touchard (t.axel@hotmail.fr) \\ Academic editor:Jack Neff | Received 8 October 2013 | Accepted 25 November 2015 | Published 22 December 2015 \\ http://zoobank.org/EAF9D841-3AB6-4EB3-82B2-18A1F241E7C5 \\ Citation: Touchard A, Dejean A, Escoubasd P, Orivel J (2015) Intraspecific variations in the venom peptidome of the ant \\ Odontomachus haematodus (Formicidae: Ponerinae) from French Guiana. Journal of Hymenoptera Research 47: 87-101. \\ doi: 10.3897/JHR.47.6804
}

\begin{abstract}
Ant venoms are complex cocktails of toxins employed to subdue prey and to protect the colony from predators and microbial pathogens. Although the extent of ant venom peptide diversity remains largely unexplored, previous studies have revealed the presence of numerous bioactive peptides in most stinging ant venoms. We investigated the venom peptidome of the ponerine ant Odontomachus haematodus using LC-MS analysis and then verified whether the division of labor in the colonies and their geographical location are correlated with differences in venom composition. Our results reveal that $O$. haematodus venom is comprised of 105 small linear peptides. The venom composition does not vary between the different castes (i.e., nurses, foragers and queens), but an intraspecific variation in peptide content was observed, particularly when the colonies are separated by large distances. Geographical variation appears to increase the venom peptide repertoire of this ant species, demonstrating its intraspecific venom plasticity.
\end{abstract}

\section{Keywords}

Ant venoms, MALDI-TOF MS, Odontomachus haematodus, peptidome, polyethism

Copyright Axel Touchard et al. This is an open access article distributed under the terms of the Creative Commons Attribution License (CC BY 4.0), which permits unrestricted use, distribution, and reproduction in any medium, provided the original author and source are credited. 


\section{Introduction}

Due to their ubiquity in terrestrial environments, ants are amongst the most abundant venomous animals on Earth; for instance, they represent $15-20 \%$ of the animal biomass in tropical forests (Hölldobler and Wilson 1990). Among ants, ca. 9100 species belonging to 16 subfamilies possess a stinging apparatus, while other subfamilies have lost their ability to sting (Hölldobler and Wilson 1990). Ant venoms contain a variety of toxins that paralyze prey, ward off predators and protect the colony against microbial pathogens (Orivel et al. 2001; Schmidt 1982). As they have been little studied, ant venom peptides represent a potentially promising source of bioactive molecules with novel scaffolds and original pharmacological activities. Previous studies (Aili et al. 2014; Touchard et al. 2014; Touchard et al. 2015) have demonstrated that the venoms of stinging ants are mostly comprised of small peptides, similarly to spider, scorpion and cone snail venoms. A limited number of peptidic toxins from several ant subfamilies such as the Ponerinae (Cologna et al. 2013; Johnson et al. 2010; Orivel et al. 2001), Paraponerinae (Piek et al. 1991), Ectatomminae (Arseniev et al. 1994; Pluzhnikov et al. 2000), Myrmicinae (Rifflet et al. 2012), Myrmeciinae (Inagaki et al. 2004; Inagaki et al. 2008) and Pseudomyrmecinae (Pan and Hink 2000) have been characterized.

One of the major issues in the biochemical and pharmacological study of venoms is the reproducibility of studies conducted on field-collected samples, which requires accurate species identification. We have previously demonstrated that, at the species level, the peptidic fingerprints of ant venoms are reliable chemotaxonomic markers for species determination and may possibly allow the discrimination of unresolved species complexes (Touchard et al. 2014). However, intraspecific variations can also occur as shown recently in Dinoponera quadriceps for which only 48 peptides were shared between colonies out of the more than 300 peptides found in total (Cologna et al. 2013). Also, intraspecific variations in venom composition have been observed in snakes, scorpions, tarantulas and cone snails, this variation being linked to geographical distribution (Núnez et al. 2009; Shashidharamurthy et al. 2002), age (Escoubas et al. 2002) or sex (Escoubas et al. 1997; Herzig and Hodgson 2009; Herzig et al. 2002; Herzig et al. 2008). However, it remains unclear whether such variation is a common denominator for all venomous animals or is restricted to some taxa or species. This key point is still a subject of debate amongst specialists, since venom sampling conditions are often limiting and broad species-wide surveys of venom composition have been difficult to conduct.

In ants as in all hymenopterans, only females are venomous, so that sex cannot account for venom variation. Therefore, intraspecific variations in venom composition could be related to geographical distribution, diet, age or division of labor (polyethism). In most ant species, reproduction is carried out by the queen(s), while all other tasks are performed by the workers for whom the division of labor is based on physical caste (there is polymorphism in the worker caste) or, most often, age (Fresneau 1994). Usually, the youngest workers are involved in intranidal activities, whereas older workers are assigned to tasks outside the nest such as defense and foraging (da Silva-Melo and Giannotti 2012; Sendova-Franks and Franks 1999; Wilson 1963). 
As venom is mostly used by workers performing extranidal activities, one can hypothesize that polyethism could affect venom composition. To test this hypothesis, we investigated both intracolonial and intercolonial variations in venom composition in the Neotropical ponerine species, Odontomachus haematodus. The monomorphic workers of this species possess a peptide-rich venom (Touchard et al. 2014) used in colony defense and prey capture. To assess possible venom variations, we characterized the entire venom peptidome by combining HPLC chromatographic separation with offline MALDI-TOF mass spectrometry analysis and explored the putative differences in venom composition between castes and type of activity (i.e., queens, and worker nurses and foragers) as well as colonies from different geographical locations via the comparison of their venom peptidic fingerprints.

\section{Materials and methods}

\subsection{Ant collection and taxonomy}

Odontomachus haematodus colonies were collected from three different areas in French Guiana: six colonies were collected on the Campus Agronomique, Kourou; three in Sinnamary; and one in Angoulême (Fig. 1). In the laboratory, the ant colonies were conserved in artificial nests made of plastic boxes $(11 \mathrm{~cm} \times 11 \mathrm{~cm} \times 6 \mathrm{~cm})$ filled with $2 \mathrm{~cm}$ of molded plaster to create chambers and covered by a plate of red glass. These boxes were connected to a foraging arena consisting of a second, similar plastic box without plaster. The colonies were kept at $25^{\circ} \mathrm{C}$ and provided with dead mealworms and honey twice a week.

Voucher specimens werle deposited in the Laboratorio de Mirmecologia, Cocoa Research Centre, Ilhéus, Bahia, Brazil.

\subsection{Behavioral observations and ant groups}

To investigate the division of labor, workers were individually marked with different colored dots of paint on their thoraxes and gasters. Worker tasks were determined by scan sampling their behavior (three scans per day at 9:00 am, 2:00 pm and 5:00 pm; 5 days per week over 3 weeks). The percentage of presence in the foraging area for each individual over the 3 -week period was calculated to define the behavioral groups. Workers that had either never been seen in the foraging area or were there between $0 \%$ to $25 \%$ of the time were considered nurses ([group 0\%] and [group 25\%], respectively). Those observed between $25 \%$ to $50 \%$ of the time in the foraging area were considered intermediates [group 50\%], and those observed between $50 \%$ to $75 \%$ or between $75 \%$ to $100 \%$ of the time in the foraging area were considered foragers ([group 75\%] and [group 100\%], respectively). Moreover, winged females present in the colonies were named "virgin queens" in order to differentiate them from "reproductive queens" devoid of wings (see Fig. 1). 


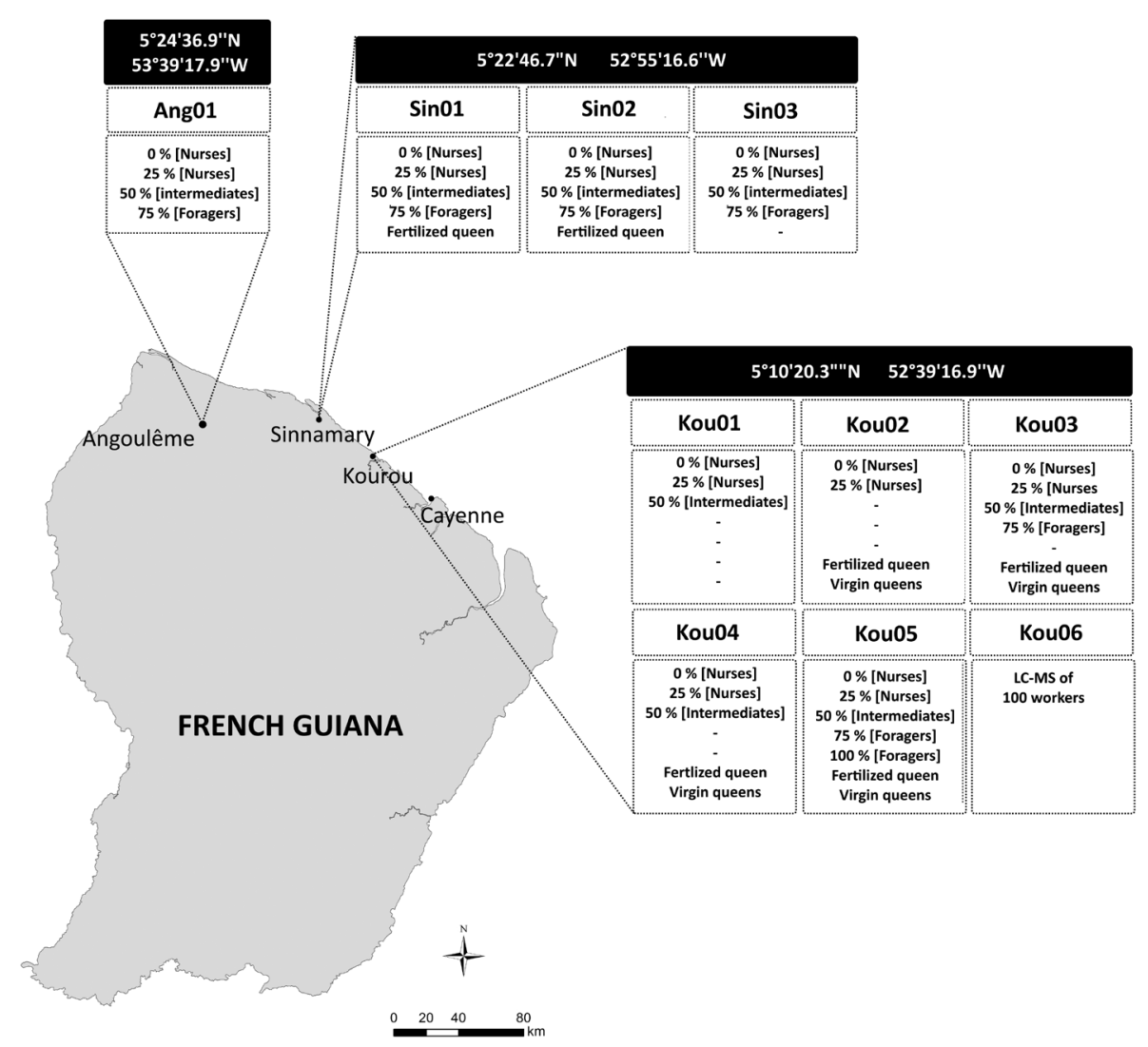

Figure I. Sites where the 10 Odontomachus haematodus colonies were collected in French Guiana. Table panels show information about each colony, including GPS coordinates, colony code and the different behavioral groups. One hundred dissected workers from colony Kou06 were used for LC-MS investigation.

\subsection{Venom analysis}

Ants were killed by freezing at $-20{ }^{\circ} \mathrm{C}$ prior to dissecting their venom glands. The dissected venom glands were placed in $10 \%$ acetonitrile $(\mathrm{ACN}) /$ water $(\mathrm{v} / \mathrm{v})$, centrifuged for $5 \mathrm{~min}$ at 14,400 rpm and the supernatant was collected and lyophilized prior to storage at $-20{ }^{\circ} \mathrm{C}$ for subsequent biochemical analysis. To study intra-colonial variations and the influence of the role of individual ants in the colony, five venom glands from each behavioral group (cf. Fig. 1) were dissected and pooled for each colony. Furthermore, 100 venom glands from the workers of one colony (Kou06; $3.55 \mathrm{mg}$ of dry crude venom in total) were dissected to carry out an in-depth exploration of the whole venom by LC-MS. 


\subsection{Chromatographic separation}

In order to fully explore the Odontomachus haematodus peptidome, a venom sample pooled from 100 workers was fractionated by reversed-phase high performance liquid chromatography (RP-HPLC) on a Waters Xterra-C18 5 $\mu \mathrm{m}, 2.1 \times 100 \mathrm{~mm}$ column with an Agilent HP 1100 HPLC system. Fractionation was achieved using a gradient of solvent A (water / 0.1\% trifluoroacetic acid TFA) and solvent B (ACN / 0.1\% TFA). The percentage of solvent $\mathrm{B}$ was modified at a flow rate of $0.3 \mathrm{~mL} / \mathrm{min}$ as follows: $0 \%$ for $5 \mathrm{~min}, 0-60 \%$ for $60 \mathrm{~min}, 60-90 \%$ for $10 \mathrm{~min}$ and $90-0 \%$ for $15 \mathrm{~min}$. The absorbance of the column effluent was monitored at $215 \mathrm{~nm}$ on a diode-array detector. The signal was monitored in real time, and fractions were collected manually for each eluting peak. Individual fractions were then dried and reconstituted in $50 \mu \mathrm{L}$ of water $/ 0.1 \%$ TFA for subsequent off-line MALDI-TOF MS analysis and disulfide bond reduction.

\subsection{Chemical reduction of disulfide bonds}

To map the distribution of disulfide-linked peptides in the venom, $5 \mu \mathrm{L}$ of each fraction were incubated in $10 \mu \mathrm{L}$ of a reducing buffer (100 mM Tris, $\mathrm{pH} 8,6 \mathrm{M}$ guanidine) with $10 \mathrm{mM}$ dithiothreitol (DTT) for $1 \mathrm{~h}$ at $56^{\circ} \mathrm{C}$ in the dark. The reaction was stopped by the addition of $5 \mu \mathrm{L}$ of water / TFA $0.1 \%$. Prior to mass spectrometry analysis, reduced fractions were desalted using Ziptip ${ }^{\circ} \mathrm{C} 18$ (Millipore) pipette tips. As the chemical reduction of disulfide bonds results in a mass increase of $2 \mathrm{Da}$ for each bond, comparing mass shifts between native and reduced venom fractions allowed the presence of disulfide-linked peptides and the number of disulfide bonds for each to be compared.

\subsection{Mass spectrometry analysis}

Mass spectrometry analyses were performed on a Voyager DE-Pro MALDI-TOF mass spectrometer (Applied Biosystems; CA, USA) using $\alpha$-cyano-4-hydroxycinnamic acid (CHCA) matrix dissolved at $5 \mathrm{mg} / \mathrm{mL}$ in water/ACN/TFA $(50 / 50 / 0.1 \mathrm{v} / \mathrm{v} / \mathrm{v})$. Prior to MS analysis, crude venoms were desalted using Ziptip ${ }^{\circ} \mathrm{C} 18$ (Millipore) pipette tips. Then, $1 \mu \mathrm{L}$ of each reconstituted HPLC fraction or the desalted crude venom was deposited on the MALDI target plate followed by $1 \mu \mathrm{L}$ of the matrix. Each spectrum was calibrated externally using a mixture of peptides of known molecular masses in the same $m / z$ range (Peptide calibration Mix 4, LaserBio Labs, Sophia-Antipolis, France). External calibration was performed by depositing, adjacent to each sample, $0.5 \mu \mathrm{L}$ of the calibration mixture co-crystallised with $0.5 \mu \mathrm{L}$ of the CHCA matrix. All spectra were acquired in reflector mode to maximize the accuracy of the mass determination. Spectra were collected over the $\mathrm{m} / \mathrm{z} 500-10,000$ range in positive ion mode (200 shots per spectrum) and were automatically calibrated using the sequence module of the Voyager ${ }^{\bullet}$ control software (Applied Biosystems, USA). 


\subsection{Data analysis}

The mass spectra were subjected to a baseline correction ( 0.7 correlation factor) and Gaussian smoothing (5-point filter width) using Data Explorer ${ }^{\circledR} 4.11$ software. Potential sodium and potassium adducts were manually removed from all mass lists. Masses matching within $\pm 1.0 \mathrm{Da}$ were defined as identical peptides in this study. Identical masses in adjoining HPLC fractions, which were interpreted as reflecting an incomplete separation, were also removed. Two-dimensional scatter plots, termed "2D venom landscapes", were constructed using SigmaPlot 12.0 software. All peptide masses detected in the HPLC fraction spectra were plotted as dot graphs with $m / z$ values $s$ on the $y$-axis and RP-HPLC elution time on the $\mathrm{x}$-axis. A Principal Component Analysis (PCA) of the relative abundance of peptides in the mass spectra was performed using PAST 3.02 software.

\section{Results}

\subsection{Venom peptidome analysis}

The LC-MS analysis of Odontomachus haematodus venom revealed the presence of 105 peptides (Table 1). All of the peptides are small, falling within a narrow mass range of $m / z 777.49$ to $2978.5\left(\mathrm{M}+\mathrm{H}^{+}\right)$(Fig. 2A-B). We estimated that the number of residues varied between 7 and 27 based on a theoretical estimate of $\mathrm{MW}_{\mathrm{av}}$ of 111.1254 $\mathrm{Da}$ for an average amino acid (Averagine). The value is derived from the statistical occurrence of amino acids in proteins (Senko et al. 1995), and calculated with the formula $\mathrm{C}_{4.9384} \mathrm{H}_{7.7583} \mathrm{~N}_{1.3577} \mathrm{~S}_{0.0417}$. All of the peptides eluted between 15\% and 45\% ACN (retention time: $20-50 \mathrm{~min}$ ), with the most abundant peptides in the venom eluting between 35\% and 45\% ACN (retention time: 40-50 min) (Fig. 2C).

Table I. Mass list of peptides $(\mathrm{m} / \mathrm{z})$ from $O$. haematodus venom collected in Kourou (Kou06).

\begin{tabular}{llllllll}
\hline 777.49 & 800.84 & 809.31 & 822.3 & 877.45 & 888.6 & 890.5 & 932.5 \\
937.4 & 945.4 & 950.49 & 973.73 & 987.76 & 1003.5 & 1008.4 & 1010.5 \\
1016.43 & 1044.73 & 1047.5 & 1058.75 & 1064.7 & 1078.65 & 1107.79 & 1283.67 \\
1127.6 & 1130.56 & 1134.57 & 1186.93 & 1194.65 & 1248.6 & 1274.79 & 1383.67 \\
1316.85 & 1320.81 & 1358.8 & 1360.6 & 1370.7 & 1375.7 & 1376.78 & 1380.62 \\
1421.7 & 1429.9 & 1447.8 & 1473.87 & 1497.87 & 1500.92 & 1518.84 & 1522.8 \\
1694.07 & 1714.04 & 1725.12 & 1729.92 & 1731.93 & 1756.06 & 1774.1 & 1792.07 \\
1803.06 & 1818.96 & 1854.07 & 1857.9 & 1863.2 & 1872.07 & 1906.24 & 1917.09 \\
1933.01 & 1963.01 & 1968.14 & 1978.03 & 1979.02 & 2010.27 & 2020.02 & 2044.97 \\
2048.02 & 2063.09 & 2078.04 & 2079.15 & 2086.73 & 2088.3 & 2096.12 & 2111.17 \\
2117.24 & 2137.08 & 2139.08 & 2157.2 & 2245.25 & 2254.22 & 2272.47 & 2430.3 \\
2448.2 & 2461.28 & 2473.3 & 2515.39 & 2590.34 & 2637.36 & 2655.33 & 2766.48 \\
2784.62 & 2785.8 & 2789.47 & 2790.4 & 2802.38 & 2805.4 & 2944.5 & 2960.52 \\
2978.5 & & & & & & & \\
\hline
\end{tabular}



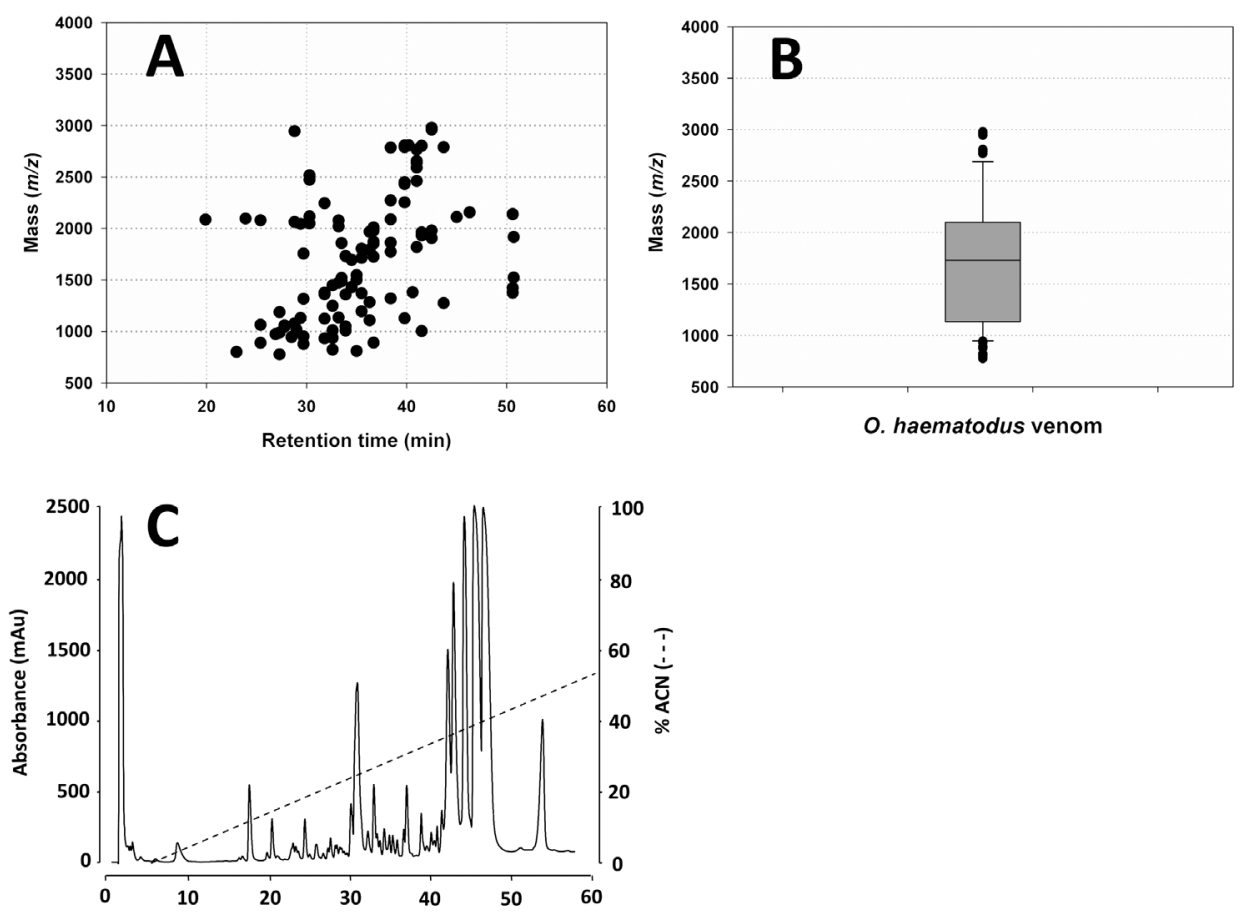

Figure 2. Investigation of the whole Odontomachus haematodus venom peptidome by LC-MS. (A) Twodimensional landscape of the venom. Dots indicate peptides. (B) Box-and-whisker plot of the peptide mass distribution presented in the $2 \mathrm{D}$ venom landscape. The bottom and top ends of the box represent the first and third quartiles, respectively, while the line inside each box represents the median mass. The ends of the whiskers represent the 5-95 percentile range while the dots represent masses outside the 5-95 percentile range. (C) C18 RP-HPLC chromatogram of the venom. The dashed line shows the slope of the ACN gradient.

The mass analysis of the chemically reduced HPLC fractions did not show any mass shift between native and reduced fractions, demonstrating that Odontomachus haematodus venom is exclusively composed of linear peptides (i.e., devoid of disulfide bonds).

\subsection{Venom peptidome variations}

We collected 43 venom samples from the nine Odontomachus haematodus colonies monitored: 18 venoms from nurses; eight from intermediates, seven from foragers, six from fertilized queens and four from virgin queens. The MALDI-TOF MS peptidic mass fingerprinting of these 43 crude venoms resulted in the selection of the 20 characteristic peptides masses (i.e., showing the most abundant signals) which constituted the matrix used for the principal component analysis (PCA) $(\mathrm{m} / \mathrm{z} 1842.6,1861.1,1916.91$, 1962.89, 2019.91, 2044.69, 2062.27, 2086.03, 2095.89, 2117.03, 2219.16, 2245.32, $2387.28,2473.22,2515.32,2590.18,2679.79,2784.34,2789.25,2802.39)$. 
A PCA based on the relative abundance of the selected peptides revealed that the first two principal components accounted for $68.1 \%$ of the variance (Fig. 3). The PCA showed that the venom composition was not related to caste or type of activity (Fig. 3). Indeed, venoms from different behavioral groups showed similar patterns, indicating that polyethism and reproductive status did not affect the peptidic composition of the venoms (Fig. 4). Yet, some qualitative intracolonial differences were noted in the behavioral groups as illustrated by the nurse group (Fig. 5).

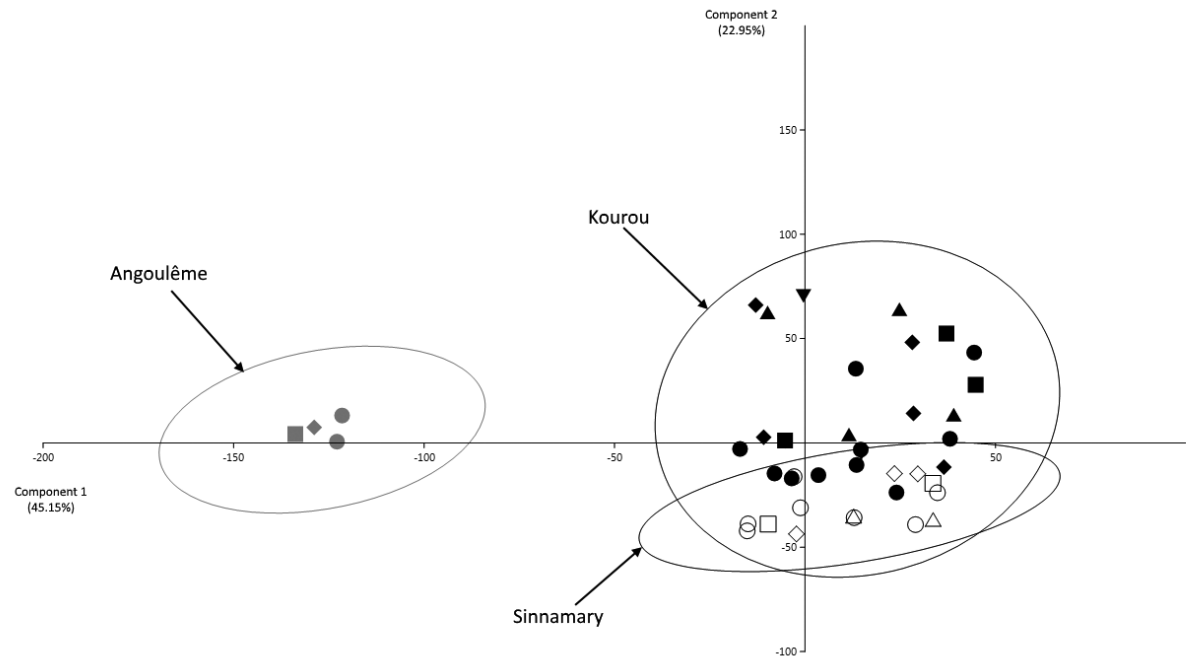

Figure 3. Ordination diagram based on the principal components of the relative abundance of peptides from 43 Odontomachus haematodus venoms. Solid symbols represent ant venoms from Kourou, empty symbols represent ant venoms from Sinnamary and grey symbols are venoms from Angoulême. The 95\% confidence ellipses are displayed. The different behavioral groups and castes are shown by the following shapes: circle [nurses]; diamond [intermediates]; square [foragers]; triangle [reproductive queens] and inversed triangle [virgin queens].

The venoms from Angoulême, which contained two specific peptides $(\mathrm{m} / \mathrm{z} 1861.1$ and 2062.27), were separated from those from the two other localities and differed only by the relative proportions of the mass $2019.91 \mathrm{~m} / \mathrm{z}$ (Fig. 3).

\section{Discussion}

Ant venoms are complex cocktails of peptides which have evolved to act on multiple biological targets. By combining MALDI-TOF MS with chromatographic separation, we have shown that the Odontomachus haematodus venom peptidome is composed of more than 100 small and linear peptides in the 700-3000 m/z mass range. This feature is consistent with a previous study on the venoms of five Neotropical Odontomachus species (Touchard et al. 2014) as well as wasp and cone snail venoms which are usually comprised of peptides with fewer than 35 residues (Baptista-Saidemberg et al. 2011; 


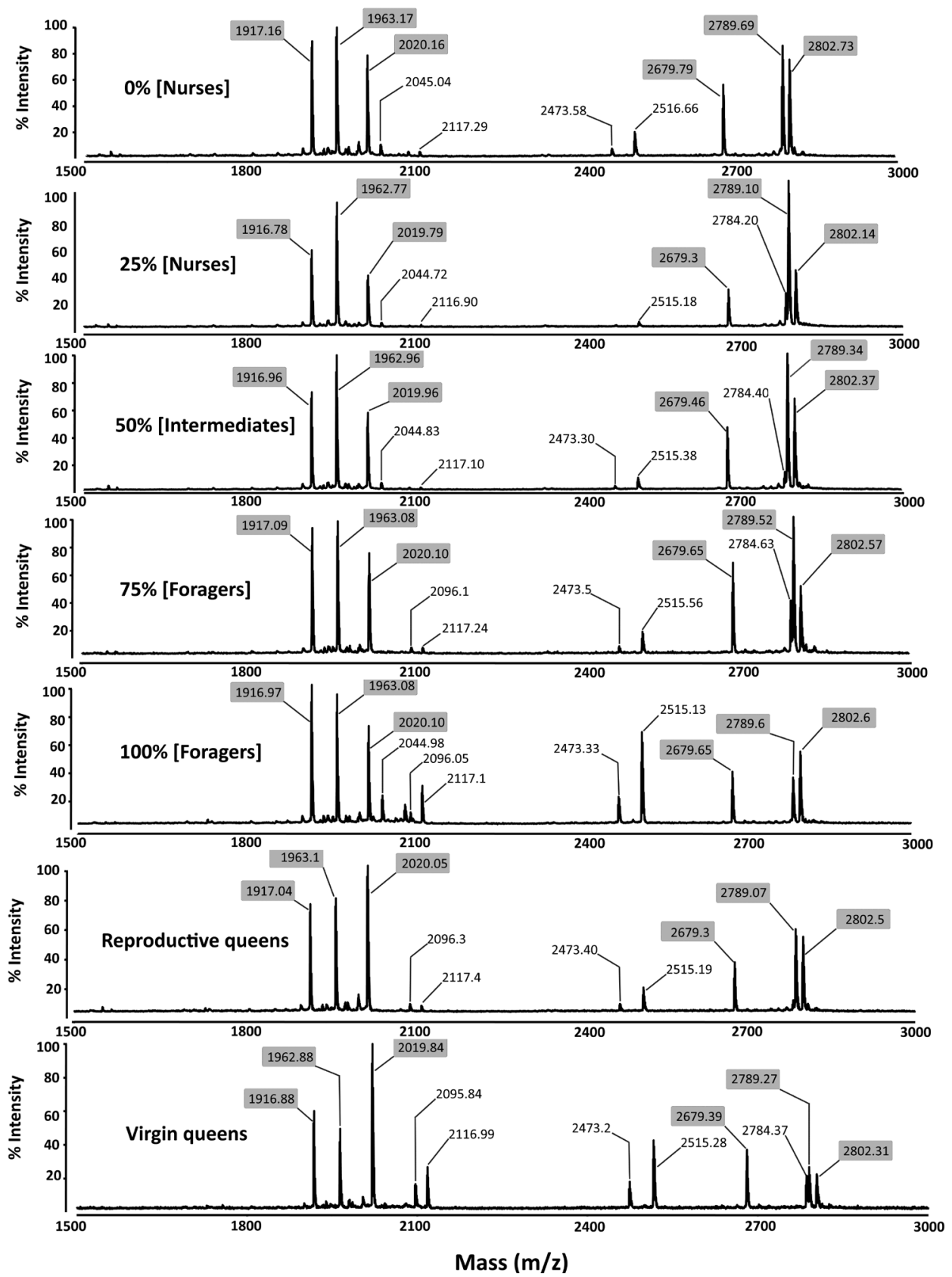

Figure 4. Intracolonial mass spectra variations among the different behavioral groups of colony Kou05. Few qualitative variations can be observed and many dominant peptides were present in all groups, particularly the shaded masses. 

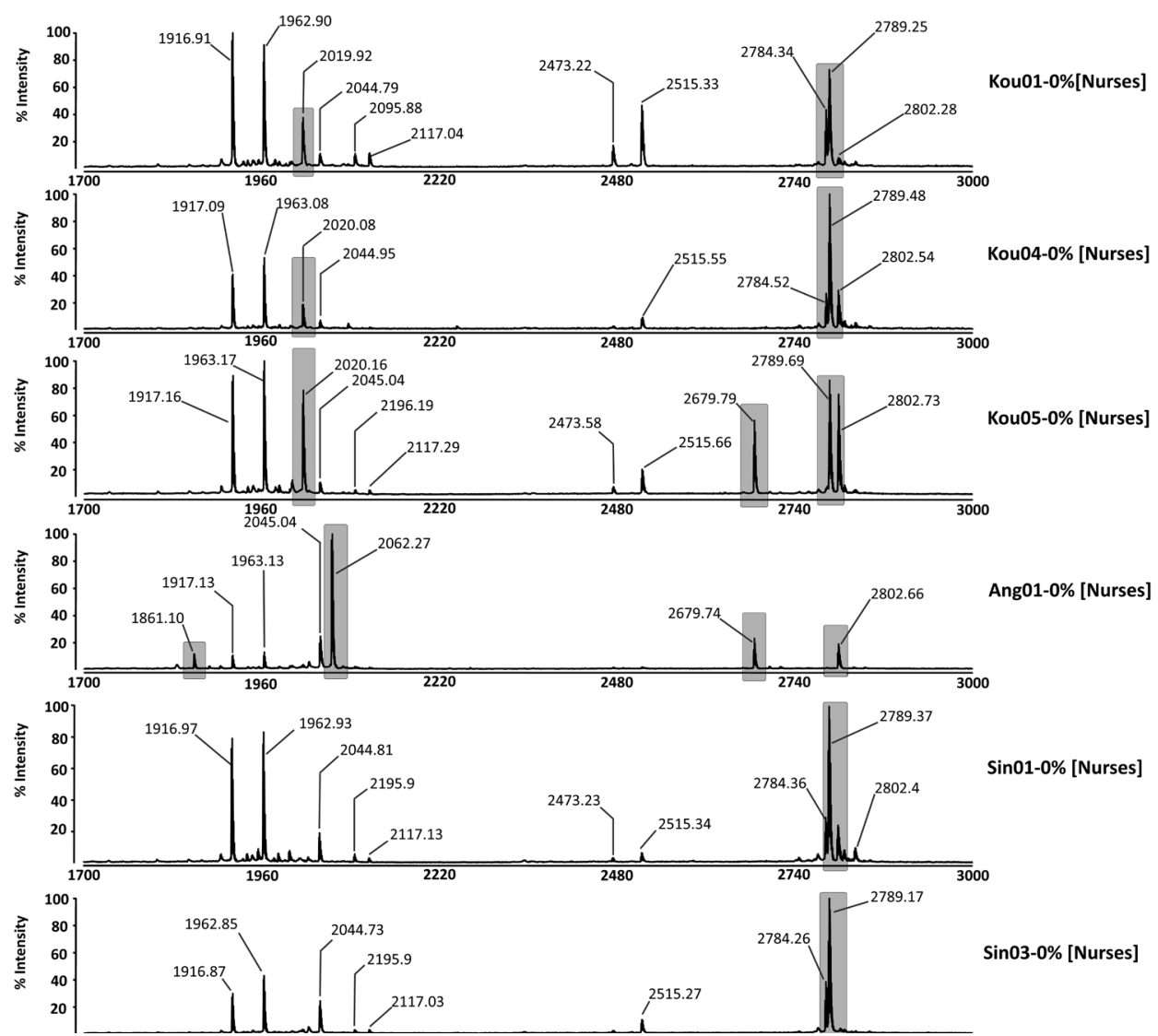

Figure 5. Intercolonial mass spectra variation among the nurses [0\% group]. Shaded areas highlight major mass variations among the different Odontomachus haematodus colonies.

Cologna et al. 2013; de Souza et al. 2004; Gomes et al. 2014; Johnson et al. 2010; Lewis et al. 2012; Orivel et al. 2001). In contrast, spider, scorpion and snake venoms may also contain larger peptides with typically from 30 to 100 amino acids (Olivera et al. 1990).

Because the presence of peptides and proteins in venoms is associated with the metabolic cost of venom production, we hypothesized that ants dedicated to tasks within the nest, typically nurses and queens, may possess less complex venoms than foragers, the latter using their venom to subdue prey and deter enemies and therefore needing venoms with a higher level of efficacy. Yet, our results show that the venom composition does not differ between nurses, intermediates, foragers or even queens in Odontomachus haematodus. By comparison, the toxicity of Neoponera commutata (Ponerinae) worker venoms was not related to age or task specialization, but the workers from different behavioral castes possess different amounts of venom in their reservoir (Schmidt and Overal 2009). Also, callow Harpegnathos saltator (Ponerinae) workers have empty venom sacks, and workers dedicated to tasks inside the nest have lower 
amounts of venom than do older ones (Haight 2012). Therefore, we can hypothesize that, in most Ponerinae, nurses limit the metabolic cost of venom by producing lower amounts, but with the same peptidic composition as the foragers. Interestingly, these results contrast with the case of fire ants whose alkaloid venom composition changes with the size and age of the workers (Deslippe and Guo 2000; Haight and Tschinkel 2003). The venom composition of all fire ant queens is also presumably different from workers which assumes different biological effects (Eliyahu et al. 2011; Fox et al. 2012). Also, Neoponera commutata (Ponerinae) and Pogonomyrmex spp. (Myrmicinae) queens produce less venom than do workers and their venom is significantly less lethal and paralytic than that of the workers, suggesting differences in venom composition (Schmidt and Overal 2009; Schmidt and Schmidt 1985).

In Odontomachus haematodus, differences in venom composition seem rather associated with geographic variations as the venom peptidic fingerprints clearly differed between colonies, particularly if they came from locations separated by large distances. Such inter-colonial variations have previously been reported for Dinoponera quadriceps (Ponerinae) collected from different areas in Brazil (Cologna et al. 2013). Among animal venoms, intraspecific variations related to geography are a common phenomenon and have been reported in snakes (Shashidharamurthy et al. 2002), cone snails (Duda et al. 2009), scorpions (Omran and McVean 2000), spiders (Escoubas et al. 1998) and both social (Dias et al. 2014) and parasitoid wasps (Poirié et al. 2014). In snakes, intraspecific variations have been shown to exhibit a differential venom effectiveness towards different prey (Casewell et al. 2013). This may be the result of allelic variations in the genes coding the peptides as shown for Conus ebraeus venom (Duda et al. 2009), increasing the venom peptidic diversity in this species. This intraspecific diversity is essential for natural selection and ant venom diversification.

Previous studies have demonstrated that toxins (peptide and alkaloids) in ant venoms can be used as chemotaxonomic markers in order to identify species but also to reveal cryptic ant species (Fox et al. 2012; Touchard et al. 2014). Thus, the observed intraspecific variation in the venom composition of Odontomachus haematodus might also result from the presence of cryptic species. It would be interesting in the future to extend this study through further genetic analysis to assess the possible presence of different cryptic species.

\section{Conclusion}

The present study constitutes the first exploration of the Odontomachus haematodus venom peptidome, revealing that this venom is comprised of more than 100 small linear peptides. Also, the peptidic diversity in this species is amplified due to intraspecific variations. The present results show that these venom variations are not related to caste or type of activity, but seem to be related to the geographical location of the ant colonies or to a hypothetical complex of cryptic species. It would be interesting in the future to analyze whether such variations can affect the effectiveness of the venom 
in prey capture. It will also be necessary to consider such intercolonial variations in peptidic composition to ensure the reproducibility of further biochemical and pharmacological studies on ant venoms.

\section{Acknowledgments}

We are grateful to Andrea Yockey-Dejean for proofreading the manuscript. Financial support for this study was provided by the programme Convergence 2007-2013, Région Guyane from the European Community (Bi-Appli, 115/SGAR-DE-2011/052274) and the BIOPEPMED grant from the Programme Amazonie II of the French Centre National de la Recherche Scientifique. This study has also benefited from a "Investissement d'Avenir" grant managed by the Agence Nationale de la Recherche (CEBA, ref. ANR-10- LABX-25-01).

\section{References}

Aili SR, Touchard A, Escoubas P, Padula MP, Orivel J, Dejean A, Nicholson GM (2014) Diversity of peptide toxins from stinging ant venoms. Toxicon 92: 166-178. doi: 10.1016/j. toxicon.2014.10.021

Arseniev AS, Pluzhnikov KA, Nolde DE, Sobol AG, Torgov M, Sukhanov SV, Grishin EV (1994) Toxic principle of selva ant venom is a pore-forming protein transformer. FEBS letters 347: 112-116. doi: 10.1016/0014-5793(94)00518-4

Baptista-Saidemberg NB, Saidemberg DM, Palma MS (2011) Profiling the peptidome of the venom from the social wasp Agelaia pallipes pallipes. Journal of Proteomics 74: 2123-2137. doi: 10.1016/j.jprot.2011.06.004

Casewell NR, Wüster W, Vonk FJ, Harrison RA, Fry BG (2013) Complex cocktails: the evolutionary novelty of venoms. Trends in Ecology \& Evolution 28: 219-229. doi: 10.1016/j. tree.2012.10.020

Cologna CT, Cardoso JdS, Jourdan E, Degueldre M, Upert G, Gilles N, Uetanabaro APT, Costa Neto EM, Thonart P, de Pauw E (2013) Peptidomic comparison and characterization of the major components of the venom of the giant ant Dinoponera quadriceps collected in four different areas of Brazil. Journal of Proteomics 94: 413-422. doi: 10.1016/j. jprot.2013.10.017

da Silva-Melo A, Giannotti E (2012) Division of Labor in Pachycondyla striata Fr. Smith, 1858

(Hymenoptera: Formicidae: Ponerinae). Psyche 2012: 1-7. doi: 10.1155/2012/153862

de Souza BM, Marques MR, Tomazela DM, Eberlin MN, Mendes MA, Palma MS (2004)

Mass spectrometric characterization of two novel inflammatory peptides from the venom of the social wasp Polybia paulista. Rapid Communications in Mass Spectrometry 18: 1095-1102. doi: 10.1002/rcm.1452

Deslippe RJ, Guo Y-J (2000) Venom alkaloids of fire ants in relation to worker size and age. Toxicon 38: 223-232. doi: 10.1016/S0041-0101(99)00147-6 
Dias NB, de Souza BM, Gomes PC, Palma MS (2014) Peptide diversity in the venom of the social wasp Polybia paulista (Hymenoptera): A comparison of the intra- and inter-colony compositions. Peptides 51: 122-130. doi: 10.1016/j.peptides.2013.10.029

Duda TF Jr, Chang D, Lewis BD, Lee T (2009) Geographic variation in venom allelic composition and diets of the widespread predatory marine gastropod Conus ebraeus. PLoS ONE 4: e6245. doi: 10.1371/journal.pone.0006245

Eliyahu D, Ross KG, Haight KL, Keller L, Liebig J (2011) Venom alkaloid and cuticular hydrocarbon profiles are associated with social organization, queen fertility status, and queen genotype in the fire ant Solenopsis invicta. Journal of Chemical Ecology 37: 1242-1254. doi: 10.1007/s10886-011-0037-y

Escoubas P, Celerier M-L, Nakajima T (1998) Composition and neurotoxicity of tarantula venoms: biogeographic and taxonomic variations. Toxicon 36: 1737.

Escoubas P, Célérier M-L, Nakajima T (1997) High-performance liquid chromatography matrix-assisted laser desorption/ionization time-of-flight mass spectrometry peptide fingerprinting of tarantula venoms in the genus Brachypelma: chemotaxonomic and biochemical applications. Rapid Communications in Mass Spectrometry 11: 1891-1899. doi: 10.1002/ (SICI)1097-0231(199711)11:17<1891::AID-RCM94>3.0.CO;2-X

Escoubas P, Corzo G, Whiteley BJ, Célérier M-L, Nakajima T (2002) Matrix-assisted laser desorption/ionization time-of-flight mass spectrometry and high-performance liquid chromatography study of quantitative and qualitative variation in tarantula spider venoms. Rapid Communications in Mass Spectrometry 16: 403-413. doi: 10.1002/rcm.595

Fox EGP, Pianaro A, Solis DR, Delabie JHC, Vairo BC, Machado EdA, Bueno OC (2012) Intraspecific and intracolonial variation in the profile of venom alkaloids and cuticular hydrocarbons of the fire Ant Solenopsis saevissima Smith (Hymenoptera: Formicidae). Psyche 2012: 1-10.

Fresneau D (1994) Biologie et comportement social d'une fourmi néotropicale (Pachycondyla apicalis). Unpublisher PhD Thesis.

Gomes PC, de Souza BM, Dias NB, Brigatte P, Mourelle D, Arcuri HA, dos Santos Cabrera MP, Stabeli RG, Neto JR, Palma MS (2014) Structure-function relationships of the peptide Paulistine: A novel toxin from the venom of the social wasp Polybia paulista. Biochimica et Biophysica Acta (BBA) - Biomembranes 1840: 170-183. doi: 10.1016/j.bbagen.2013.08.024

Haight KL (2012) Patterns of venom production and temporal polyethism in workers of Jerdon's jumping ant, Harpegnathos saltator. Journal of Insect Physiology 58: 1568-1574. doi: 10.1016/j.jinsphys.2012.09.011

Haight KL, Tschinkel WR (2003) Patterns of venom synthesis and use in the fire ant, Solenopsis invicta. Toxicon 42: 673-682. doi: 10.1016/j.toxicon.2003.09.005

Herzig V, Hodgson WC (2009) Intersexual variations in the pharmacological properties of Coremiocnemis tropix (Araneae, Theraphosidae) spider venom. Toxicon 53: 196-205. doi: 10.1016/j.toxicon.2008.11.002

Herzig V, John Ward R, Ferreira dos Santos W (2002) Intersexual variations in the venom of the Brazilian 'armed'spider Phoneutria nigriventer (Keyserling, 1891). Toxicon 40: 13991406. doi: 10.1016/S0041-0101(02)00136-8 
Herzig V, Khalife AA, Chong Y, Isbister GK, Currie BJ, Churchill TB, Horner S, Escoubas P, Nicholson GM, Hodgson WC (2008) Intersexual variations in northern (Missulena pruinosa) and eastern (M. bradleyi) mouse spider venom. Toxicon 51: 1167-1177. doi: 10.1016/j.toxicon.2008.02.001

Hölldobler B, Wilson E-O (1990) The Ants. Harvard University Press, Cambridge (MA), 746 pp.

Inagaki H, Akagi M, Imai HT, Taylor RW, Kubo T (2004) Molecular cloning and biological characterization of novel antimicrobial peptides, pilosulin 3 and pilosulin 4, from a species of the Australian ant genus Myrmecia. Archives of Biochemistry and Biophysics 428: 170-178. doi: 10.1016/j.abb.2004.05.013

Inagaki H, Akagi M, Imai HT, Taylor RW, Wiese MD, Davies NW, Kubo T (2008) Pilosulin 5, a novel histamine-releasing peptide of the Australian ant, Myrmecia pilosula (Jack Jumper Ant). Archives of Biochemistry and Biophysics 477: 411-416. doi: 10.1016/j. abb.2008.05.014

Johnson SR, Copello JA, Evans MS, Suarez AV (2010) A biochemical characterization of the major peptides from the venom of the giant Neotropical hunting ant Dinoponera australis. Toxicon 55: 702-710. doi: 10.1016/j.toxicon.2009.10.021

Lewis RJ, Dutertre S, Vetter I, Christie MJ (2012) Conus venom peptide pharmacology. Pharmacological Reviews 64: 259-298. doi: 10.1124/pr.111.005322

Núñez V, Cid P, Sanz L, De La Torre P, Angulo Y, Lomonte B, Gutiérrez JM, Calvete JJ (2009) Snake venomics and antivenomics of Bothrops atrox venoms from Colombia and the Amazon regions of Brazil, Perú and Ecuador suggest the occurrence of geographic variation of venom phenotype by a trend towards paedomorphism. Journal of Proteomics 73: 57-78. doi: 10.1016/j.jprot.2009.07.013

Olivera BM, Rivier J, Clark C, Ramilo CA, Corpuz GP, Abogadie FC, Mena EE, Hillyard D, Cruz L (1990) Diversity of Conus neuropeptides. Science 249: 257-263. doi: 10.1126/ science. 2165278

Omran MA, McVean A (2000) Intraspecific variation in scorpion Leiurus quinquestriatus venom collected from Egypt (Sinai and Aswan deserts). Toxin Reviews 19: 247-264. doi: 10.1081/TXR-100102322

Orivel J, Redeker V, Le Caer JP, Krier F, Revol-Junelles AM, Longeon A, Chaffotte A, Dejean A, Rossier J (2001) Ponericins, new antibacterial and insecticidal peptides from the venom of the ant Pachycondyla goeldii. Journal of Biological Chemistry 276: 17823-17829. doi: 10.1074/jbc.M100216200

Pan J, Hink WF (2000) Isolation and characterization of myrmexins, six isoforms of venom proteins with anti-inflammatory activity from the tropical ant, Pseudomyrmex triplarinus. Toxicon 38: 1403-1413. doi: 10.1016/S0041-0101(99)00233-0

Piek T, Duval A, Hue B, Karst H, Lapied B, Mantel P, Nakajima T, Pelhate M, Schmidt JO (1991) Poneratoxin, a novel peptide neurotoxin from the venom of the ant, Paraponera clavata. Comparative Biochemistry and Physiology Part B: Biochemistry and Molecular Biology 99: 487-495. doi: 10.1016/0742-8413(91)90276-Y 
Pluzhnikov K, Shevchenko L, Grishin E (2000) Ant polypeptide toxins. In: Rochat H, Martin-Eauclaire M-F (Eds) Methods and tools in biosciences and medicine: animal toxins. Birkhäuser, Basel, 90-98. doi: 10.1007/978-3-0348-8466-2_6

Poirié M, Colinet D, Gatti J-L (2014) Insights into function and evolution of parasitoid wasp venoms. Current Opinion in Insect Science 6: 52-60. doi: 10.1016/j.cois.2014.10.004

Rifflet A, Gavalda S, Téné N, Orivel J, Leprince J, Guilhaudis L, Génin E, Vétillard A, Treilhou M (2012) Identification and characterization of a novel antimicrobial peptide from the venom of the ant Tetramorium bicarinatum. Peptides 38: 363-370. doi: 10.1016/j. peptides.2012.08.018

Schmidt JO (1982) Biochemistry of insect venoms. Annual Review of Entomology 27: 339368. doi: 10.1146/annurev.en.27.010182.002011

Schmidt JO, Overal WL (2009) Venom and task specialization in Termitopone commutata (Hymenoptera: Formicidae). Journal of Hymenoptera Research 18: 361-367.

Schmidt P, Schmidt J (1985) Queen versus worker venoms: are they equally lethal? Toxicon 23: 38-39. doi: 10.1016/0041-0101(85)90102-3

Sendova-Franks AB, Franks NR (1999) Self-assembly, self-organization and division of labour. Philosophical Transactions of the Royal Society of London, Series B (Biological sciences) 354: 1395-1405. doi: 10.1098/rstb.1999.0487

Senko MW, Beu SC, McLaffertycor FW (1995) Determination of monoisotopic masses and ion populations for large biomolecules from resolved isotopic distributions. The American Society for Mass Spectrometry 6: 229-233. doi: 10.1016/1044-0305(95)00017-8

Shashidharamurthy R, Jagadeesha D, Girish K, Kemparaju K (2002) Variation in biochemical and pharmacological properties of Indian cobra (Naja naja naja) venom due to geographical distribution. Molecular and Cellular Biochemistry 229: 93-101. doi: 10.1023/A:1017972511272

Touchard A, Dauvois M, Arguel M-J, Petitclerc F, Leblanc M, Dejean A, Orivel J, Nicholson GM, Escoubas P (2014) Elucidation of the unexplored biodiversity of ant venom peptidomes via MALDI-TOF mass spectrometry and its application for chemotaxonomy. Journal of Proteomics 105: 217-231. doi: 10.1016/j.jprot.2014.01.009

Touchard A, Koh JMS, Aili SR, Dejean A, Nicholson GM, Orivel J, Escoubas P (2015) The complexity and structural diversity of ant venom peptidomes is revealed by mass spectrometry profiling. Rapid Communications in Mass Spectrometry 29: 385-396. doi: 10.1002/ rcm.7116

Wilson EO (1963) The social biology of ants. Annual Review of Entomology 8: 345-368. doi: 10.1146/annurev.en.08.010163.002021 